\title{
Corporeidade e yoga na educação infantil: experiências e descobertas
}

\author{
Corporeity and yoga in early childhood education: experiences and discoveries \\ Corporeidad y yoga en educación infantil: experiencias y descubrimientos \\ FERNANDA ROSSI ${ }^{1}$ \\ Universidade Estadual Paulista "Júlio de Mesquita Filho", UnesP, BaURU-SP, Brasil
}

\begin{abstract}
RESUMO
Pretendemos neste artigo estabelecer uma aproximação entre a corporeidade, a educação infantil e a vivência do yoga na infância. Para promover esse encontro, lançamos um olhar fenomenológico para as experiências das crianças com base nos pressupostos da corporeidade e da motricidade como condição existencial e de criação do mundo. As reflexões resultam de uma proposta de vivências em yoga, com duração de um ano, realizada com crianças de quatro e cinco anos de idade provenientes de duas escolas públicas municipais de Bauru-SP. O entrelaçamento proposto evidenciou a elaboração de um saber corporal direcionado para a percepção e conhecimento de si e para a escuta, a sensibilidade e os afetos na relação com o outro.
\end{abstract}

Palavras-chave: Corporeidade. Motricidade. Educação Infantil. Yoga.

\begin{abstract}
In this article, we intend to establish an approximation between corporeality, early childhood education and the experience of yoga in childhood. To promote this meeting, we take a phenomenological look at the children's experiences based on the assumptions of corporeality and motricity as an existential condition and creation of the world. The reflections result from a proposal of experiences in yoga, lasting one year, performed with children between four and five years old from two public schools in Bauru-SP. The proposed interlacing evidenced the elaboration of a corporal knowledge directed to the perception and knowledge of oneself and to listening, sensitivity and affections in the relationship with the other.
\end{abstract}

Keywords: Corporeality. Motricity. Early Childhood Education. Yoga.

\section{RESUMEN}

En este artículo pretendemos establecer una aproximación entre la corporeidad, la educación de la primera infancia y la experiencia del yoga en la infancia. Para promover esta reunión, damos una mirada fenomenológica a las experiencias de los niños basadas en los supuestos de corporeidad y motricidad como condición existencial y creación del mundo. Las reflexiones son el resultado de una propuesta de experiencias en yoga, que dura un año, con niños de cuatro y cinco años realizado com dos escuelas públicas en Bauru-SP. El entrelazado propuesto evidenciaba la elaboración de un conocimiento corporal dirigido a la percepción y el conocimiento de uno mismo y a la escucha, la sensibilidad y el afecto en la relación con el otro.

Palabras clave: Corporeidad. Motricidad. Educación Infantil. Yoga.

\footnotetext{
${ }^{1}$ Professora Assistente Doutora do Departamento de Educação da Faculdade de Ciências da UNESP Bauru. Email: fernandarossiunesp@gmail.com. ORCID: http://orcid.org/0000-0002-4760-4712.
} 


\section{INTRODUÇÃO}

$\mathrm{Na}$ tentativa de superar as dicotomias da herança cartesiana que relegava ao corpo um lugar de inferioridade no dualismo psicofísico (corpo e alma, consciência e mundo, ser humano e natureza, sujeito e objeto), o pensamento fenomenológico recusa tais separações dominantes tanto na filosofia quanto na ciência, propondo a unicidade sujeito e mundo. Expoente dessa corrente, o filósofo francês Maurice Merleau-Ponty (1908-1961) funda a reflexão sobre o ser humano como um todo indissociável e a noção de mundo.

Ao centrar no ser-mundo, Merleau-Ponty quer resgatar a condição sensível do sujeito que ao mesmo tempo é propriedade da matéria, mas também da consciência. E a categoria que supera a dicotomia entre coisa e pensamento (percepção x pensamento; sensível x inteligível, visibilidade x consciência) é o corpo.

Considerando a compreensão de corpo como "[...] modo fundamental de ser e de estar no mundo" (CHAUÍ, 2000, p. 311), a ontologia fenomenológica aborda a subjetividade reconhecendo que o "eu" está em constante transformação. Estar no mundo não é precedido por nenhuma essência anterior. Somos seres corporificados, mas não reduzidos à dimensão física (universal e homogênea), somos situados cultural, social, política, ética, estética e historicamente, somos corpo "[...] enraizado na natureza no próprio momento em que se transforma pela cultura, nunca fechado em si mesmo e nunca ultrapassado." (MERLEAU-PONTY, 2018, p. 269). A corporeidade, pois, como condição humana, revela um corpo próprio, sensível e inteligente, que adquire e expressa significados numa concretude contextualizada, que produz história e cultura em um conjunto de possibilidades de realização contínua.

O corpo, como condição da existência, constrói sua experiência cotidianamente pela percepção de seus sentidos e é pela motricidade, como esfera primária de nossas significações (MERLEAU-PONTY, 2018), que nos apropriamos e construímos o mundo, religando a unidade sujeito-mundo pela experiência perceptiva (NÓBREGA, 2005).

As discussões sobre o corpo, a corporeidade e a motricidade foram reconfiguradas a partir de Merleau-Ponty ao associar tais concepções com a consciência, a vivência e o mundo. Nessa ótica, a corporeidade nos permite interpretar o mundo (mais do que explicar) e a significação da relação entre o pensar a si mesmo e o pensar o outro (MOREIRA, 2019).

Diante dessas considerações inicias, buscamos neste artigo estabelecer uma aproximação entre a corporeidade, a educação infantil e a vivência do yoga na infância. Para promover esse encontro, lançamos um olhar fenomenológico para a experiência das crianças com o yoga fundamentando-nos nos pressupostos da corporeidade e da motricidade como condição existencial e de criação do mundo.

Empreendemos a reflexão ${ }^{2}$ com base em vivências de yoga de crianças entre quatro e cinco anos de idade, desenvolvidas ao longo de um ano, em escolas públicas municipais da cidade de Bauru-SP. Dentre os pressupostos epistemológicos e teóricos da fenomenologia destacamos as obras de Merleau-Ponty (2006; 2018), articulando tessituras com autores e autoras que contribuem com o estudo da corporeidade, da

\footnotetext{
2 As discussões deste artigo integram a pesquisa "Corporeidade na Educação Infantil: interlocução entre a formação docente e as práticas pedagógicas" que envolvem ações com práticas corporais com as crianças e a formação continuada de professoras de Educação Física, Pedagogia, Arte e Educação Especial. Parecer do Comitê de Ética em Pesquisa: 3.261.877 - UNESP/FC/Bauru. Projeto de Ensino desenvolvido com o apoio da Pró-Reitoria de Extensão/PROEX UNESP.
} 
motricidade e da infância, como Nóbrega (2005; 2019), Moreira (2019), Zimmermann e Saura (2019), Machado (2010, 2013), Kunz e Costa (2017), dentre outros(as).

A pertinência da imersão no debate sobre o corpo e a infância se inscreve, nomeadamente, no fato de que desde cedo as crianças são submetidas a processos educacionais que ignoram a complexidade do ser humano como ser corporal e sua relação com o mundo, desconsiderando o corpo como existência, a sua pluralidade, os seus desejos. A condição corpórea de existência é por vezes subjugada, o corpo é reduzido em seu potencial perceptivo e o corpo próprio dá lugar ao corpo esvaziado, condicionado e padronizado em seus modos de ser, aprender, sentir e agir.

Diante desse cenário contemporâneo que prioriza o corpo produtivo ou o corpo como mero rascunho da presença (LE BRETON, 2013) e que reduz a aprendizagem a um processo lógico, descorporificado, estático na construção do conhecimento, forjando uma compreensão do mundo e de si apartada das percepções que o atravessam, desafianos pensar em uma educação que valorize as manifestações corporais em sua potência para a criança conhecer e reconhecer-se como corpo próprio num mundo vivido, reconhecer a corporeidade do outro e se relacionar com crianças e adultos, comunicando sentimentos e ideias. Efetivando-se, assim, processos pedagógicos significativos às crianças, que assumam a corporeidade como o pressuposto da educação na infância e que concebam e valorizem a unicidade do ser.

A educação infantil como o lugar da infância, espaço e tempo da vivência de diversas formas de práticas corporais, ao promover o encontro entre corpo, motricidade e yoga, amplia as possibilidades de construções corporais, de experiências sensoriais e relacionais, propiciando uma rede de ressignificações da corporeidade em uma arquitetura de sentido e de valor.

Machado (2010), ao aproximar o pensamento de Merleau-Ponty às noções de criança, infância e educação, atenta que a fenomenologia não é uma fórmula para a pedagogia, mas sim uma maneira de pensar que se corporifica em atitudes e contribui para a reflexão (e ação) pedagógica sobre as experiências vividas das crianças. Sendo a corporeidade uma atitude e não meramente um conceito, encontramos nas referências merleau-pontianas uma profícua possibilidade de entrelaçar corpo, motricidade, yoga e a formação na infância.

Esperamos discorrer sobre o tema sem esgotá-lo - sobretudo porque o corpo, como uma existência viva, é sempre passível de ser inventado e reinventado (NÓBREGA, 2005) - descortinando relações na expectativa de incitar novas reflexões sobre a corporeidade na educação infantil. Além disso, a filosofia fenomenológica configura-se como uma perspectiva de interrogação (ZIMMERMANN; SAURA, 2019), por isso, é uma tarefa inacabada, num movimento constante de reaprender a ver o mundo (NÓBREGA, 2019).

\section{TECENDO RELAÇÕES ENTRE A CORPOREIDADE E O YOGA NA EDUCAÇÃO INFANTIL: EXPERIÊNCIAS E DESCOBERTAS}

A motricidade é a fonte das produções humanas e meio pelo qual a criança percebe e cria o seu mundo. Corporeidade e motricidade na infância consubstanciam-se com as manifestações corporais com o experienciar das mais diversificadas formas do se-movimentar, da brincadeira, do jogo, da dança, do yoga, entre tantas outras possibilidades, atravessadas pelo imaginário, o sonho e a afetividade. Garantimos, assim, como trazem as diretrizes curriculares nacionais para a educação infantil (BRASIL, 2010), que as práticas pedagógicas promovam o conhecimento de si e do 
mundo pelas experiências sensoriais, expressivas e corporais. O movimento da criança é intencional e repleto de sentidos.

Nessa perspectiva, durante o ano letivo de 2019, uma vez por semana, cerca de 140 crianças entre quatro e cinco anos, distribuídas em oito turmas, de duas escolas municipais de educação infantil da cidade de Bauru-SP, vivenciavam o yoga com a mediação de graduandas e graduandos dos cursos de Educação Física e Pedagogia da UNESP campus de Bauru, em um trabalho coletivo com professoras, gestoras e docente-pesquisadora.

Empreendemos, nas páginas que seguem, reflexões sobre esse processo de inserção da cultura do yoga na primeira etapa da educação básica e as experiências construídas com as crianças, revelando indícios da elaboração infantil de um saber corporal (saber de si e do outro) em sua relação corpo-mundo.

Recorremos ao modo do pensar-agir fenomenológico para abordar e compreender as experiências com yoga e os sentidos a elas atribuídos pelas crianças, evidenciados em suas expressões corporais, orais e artísticas, nas rodas de conversa e manifestações que registramos no decorrer das vivências.

A fenomenologia de Merleau-Ponty, para Leopoldo e Silva (2019) é, antes, uma forma de expressão e de elucidação do vivido, daquilo que há de mais concreto. Em seus escritos a fenomenologia é retratada como "[...] um relato do espaço, do tempo, do mundo 'vividos'. É a tentativa de uma descrição direta de nossa experiência tal como ela é" (MERLEAU-PONTY, 2018, p. 1). Buscamos, então, uma filosofia que interroga a experiência e se permite por ela se mobilizar (ZIMMERMANN; SAURA, 2019).

No pensamento e na atitude fenomenológica para com o ser criança MerleauPonty pontua que ela não deve ser vista pelo adulto como objeto de conhecimento, um "adulto em miniatura" ou "[...] com uma consciência semelhante à do adulto, porém inacabada, imperfeita - essa idéia é puramente negativa. A criança possui outro equilíbrio, e é preciso tratar a consciência infantil como um fenômeno positivo" (MERLEAU-PONTY, 2006, p. 165). A criança não é nem "o mesmo" que nós nem "um outro" absoluto, tampouco impermeável ao modo adulto de ser (MACHADO, 2010). Mas, as crianças possuem modos diferenciados de interpretação e de simbolização do real que são constitutivos das culturas da infância (SARMENTO, 2005). O corpo-infância como incompleto e a criança como devir precisam ser indagados e, em seu lugar, valorizar a ideia de que cada ser constrói suas experiências de acordo com sua sensibilidade e os acontecimentos que marcam sua história, conferindo estatuto, por conseguinte, aos pontos de vista e significados das próprias crianças em relação ao seu cotidiano.

Considerando que o ato de falar não esgota a experiência vivida - muitas vezes faltam palavras para comunicar sobre o saber que experimentamos corporalmente (ZIMMERMANN; SAURA, 2019), e com o intuito de compreender mais que explicar, incentivamos as crianças a expressarem ideias, opiniões e sentimentos para dar contorno ao pensamento com narrativas que permitissem que as singularidades fossem explicitadas, que suas expressões falassem o corpo, em gesto e oralidade, como manifestações do vivido, pensado e desejado, e que vividas/compartilhadas no coletivo pudessem ressoar no cotidiano escolar e no processo da formação humana infantil.

Compartilhando do princípio de olhar à infância com delicadeza para pensar " [...] a partir da criança mesma" (MACHADO, 2010, p. 11), cabe exercitarmos esse olhar sem pré-conceitos, "Observar o mundo com olhos primeiros, com espanto e admiração - características muitas vezes atribuídas ao olhar infantil" (ZIMMERMANN; SAURA, 2019, p. 124). Além do mais, como corpos que se reinventam, estamos (nós adultos e as 
crianças) sempre em processo e é esse processo de experiência com o yoga na infância que buscamos desvelar.

\section{DA CRIANÇA QUE SE-MOVIMENTA... DA EXPERIÊNCIA QUE SE CONSTRÓI}

O corpo é a unidade e a complexidade do ser humano. É a experiência vivida do ser. É o próprio ser, pois "[...] eu não estou diante de meu corpo, estou em meu corpo, ou antes sou meu corpo" (MERLEAU-PONTY, 2018, p. 207-208). O filósofo assume tal premissa na tentativa de superar a herança do pensamento racional cartesiano de negação do corpo e primazia da inteligência trazendo a noção da experiência do corpo próprio (ZIMMERMANN; SAURA, 2019).

O corpo produz um conhecimento sensível que não é ontologicamente distinto do conhecimento intelectual ou qualquer outra natureza de conhecimento. É no conjunto de todas as suas dimensões e múltiplas significações que o sujeito é e habita o mundo, apropria-se dele e o cria, formando um sistema no qual constrói as relações com os outros, consigo, com as coisas. É a corporeidade que possibilita uma vida existencializada, a experiência de ser, uma vida humana de produção ativa cultural e histórica.

As experiências do corpo próprio na infância, pela motricidade, produzem uma sensibilidade pelos afetos, gestos, relações com os outros, mediante diferentes linguagens, como a poesia, a literatura, o jogo. Nessa linha de compreensão, apresentamos o yoga às crianças da educação infantil como uma manifestação corporal integrante da diversidade de saberes e fazeres, de modos de sentir, ser e agir. O yoga na infância está relacionado com a construção de uma experiência que é sensível e respeitosa a cada criança. A filosofia do yoga concebe o sujeito em sua completude, sem supervalorizar ou desvalorizar nenhuma de suas formas de ser no mundo.

Yoga, termo que deriva do sânscrito $y u j$, tem entre seus significados a união. Sistema filosófico originário na Índia pode ser considerado como um caminho para integrar corpo, emoções e ações. O texto considerado fundamental para o yoga - o Yoga Sutra de Patañjali - indica os oito passos do yoga: yama, nyama, ásana, pranayama, pratyahara, dharana, dhyana e samadhi (FEUERSTEIN, 2001).

Os dois primeiros passos, yamas e nyamas, são princípios ou preceitos éticos que direcionam ao respeito por si e pelos outros. $\mathrm{O}$ terceiro, ásanas, são as posturas. $\mathrm{O}$ quarto, pranayamas, refere-se à respiração. O quinto e o sexto tratam do controle dos sentidos e da concentração (pratyahara e dharana). O sétimo a meditação (dhyana). E o oitavo é o ápice do yoga, o estado de integração e transcendência (FEUERSTEIN, 2001). Os dois últimos passos, por se referirem ao mundo adulto, não são abordados com as crianças (FLAK; COULON, 2007).

Introduzir o yoga no contexto escolar é uma forma de propiciar às crianças a apropriação e ampliação do repertório cultural das práticas corporais. Porém, mais do que "aprender a fazer" yoga, nosso intuito foi potencializar as experiências do semovimentar infantil (no sentido fenomenológico do movimento problematizado por Elenor Kunz) com formas de expressão que as crianças ainda não haviam experimentado, com a intencionalidade dos gestos em detrimento de movimentos padronizados, isolados ou técnicos, visando descobertas e criações infantis, e fazer do yoga a arte do encontro com a motricidade. $\mathrm{O}$ encontro com a corporeidade.

Um movimento é aprendido quando o corpo o compreendeu, quer dizer, quando ele o incorporou ao seu "mundo", e mover seu corpo é visar as coisas através dele, é deixá-lo corresponder à sua solicitação, que se exerce sobre ele sem nenhuma representação (MERLEAU-PONTY, 2018, p. 193). 
Os ásanas, na linha do Hatha Yoga, são as posturas, expressões corporais que envolvem estabilidade, alongamento, equilíbrio, alinhamento corporal, respiração controlada e foco na consciência corporal. Na infância, têm suas denominações do sânscrito adaptadas para nomes de animais e elementos da natureza que possibilitam às crianças imaginar, sonhar, criar e se expressar em sua linguagem corporal.

A acolhida das crianças ao yoga foi animada, poucos se sentiram envergonhados no início e a participação atenta e engajada representou um crescente. A proposta sempre foi flexível e encaminhada conforme o envolvimento das crianças, seus desejos, seus ritmos, suas expressões de contentamento ou desmotivação, seus estados de quietude e de agitação.

E entre risos, rostos felizes, pulos e gritos, a imaginação e a fantasia se entrelaçavam às brincadeiras, com as crianças criando e recriando o brincar (vivo ou morto dos ásanas, pega-pega pegásana, passeio na floresta...), integrando o yoga à sua cotidianidade infantil como produtoras de cultura e não meramente receptoras. Pular como o sapinho ou rastejar como a cobra eram expressões livres que as crianças traziam em seus repertórios, que coexistiam com as posturas caraterísticas do yoga para ampliar suas formas de se-movimentar, desafiando-as ao novo. E assim foram se apropriando do cachorro olhando para baixo, cachorro olhando para cima, ponte, árvore, girafa, elefante, montanha, gato, borboleta, palmeira, avião, vela, barco, para citar alguns dos ásanas mais queridos pelas crianças.

Brincar e interagir não são simples movimentações no espaço, são gestos. É a motricidade que promove uma experiência existencial plena à criança, repleta de possibilidades para construção de si e do seu mundo, de relacionamentos, de compreensão de seu lugar no social, de diálogos, de fantasia, num movimento permanente, pois no humano "Tudo é contingência [...], no sentido em que esta maneira humana de existir não está garantida a toda criança humana por alguma essência que ela teria recebido em seu nascimento" (MERLEAU-PONTY, 2018, p. 236).

Pela brincadeira e interações cotidianas a criança se posiciona, fala, escuta, imagina, observa, deseja, simboliza, cria, sonha, aprende, torna-se autônoma, interage com os objetos e com as crianças e adultos. Antes mesmo de conceituar ou engendrar o conhecimento elaborado a criança brinca. O yoga infantil vai ao encontro da valorização do brincar em toda a sua inteireza e potencialidade "[...] individual, cultural, universal, social, natural, corporal, emocional, enfim, total" (KUNZ; COSTA, 2017, p. 15), atentando, como alertam os autores, para não promover uma "extração da vida" (p. 23) daquelas crianças com a negação do ato livre de brincar e, consequentemente, da plenitude da ludicidade.

Ao yoga lúdico agregaram-se as formas de pensar e agir, vinculando-se às brincadeiras e às demais vivências a sua filosofia com os yamas e nyamas. Sendo os valores que guiam as escolhas humanas e considerando que não são imutáveis, mas se constituem conforme o momento histórico, social e cultural e, ainda, tendo em conta as especificidades da infância, os valores presentes na filosofia do yoga passam por uma releitura e adaptação visando a que as crianças compreendam suas atitudes e condutas.

Os yamas $^{3}$ (ética social) traduzidos para o universo infantil como cultivo da verdade, evitar a violência, não se apoderar do que é dos outros, desapegar-se; e os nyamas (ética pessoal) como aprimoramento pessoal pela perseverança e autodisciplina, esforço, autoestudo e contentamento, associam-se a momentos de contação de histórias, de rodas de conversa e de brincadeiras, num processo de pensar sobre a ação (falar e

\footnotetext{
${ }^{3}$ Os yamas são: ahimsa, satya, asteya, brahmacharya e aparigraha. Já os nyamas são: saucha, santosha, tapas, svadhyaya e isvara-pranidhana (FEUERSTEIN, 2001).
} 
pensar como fazeres corporais), dialogando sobre os valores e percebendo-os em situação, ou seja, é preciso vivenciá-los, experimentá-los corporalmente e na relação com os outros.

Em uma brincadeira com alongamento para o despertar do corpo, percebendo toda sua extensão e desenho no espaço, cada criança era incentivada a se autodesafiar e, ao mesmo tempo, reconhecer seu estado perceptivo e respeitar seus limites, na interdependência do que suscitam o nyama tapas e o yama ahimsa. Tapas compreende a perseverança, a determinação, o entusiasmo e a autodisciplina (esforço para atingir objetivos, não como rigidez e disciplinamento de corpos e movimentos). O autodesafio é uma forma de tentar ir além, entretanto, esse processo deve respeitar os próprios limites, como sugere ahimsa, que remete à não-violência, valorizando o respeito ao seu corpo (a si mesmo).

Sobre essa experiência algumas crianças expressavam suas percepções: "eu fico muito acordado"; "meu corpo vai laaaa em cima"; "antes eu não gostava de alongar, agora eu gosto mais", despertando para o autocuidado: "foi mais divertido e menos dolorido", "alongar faz bem pro corpo".

As crianças, curiosas e questionadoras que são, com animação e autoconfiança demostravam suas conquistas: "olha o que eu faço... [equilibrando-se na postura da árvore]"; "o leão faz assim, tem que por a língua bemmm pra fora". As dificuldades também eram expressas corporal e verbalmente: "acho muito difícil fazer algumas coisas no yoga". Yoga é conhecer-se. São as potencialidades, capacidades e limites se revelando no corpo próprio, o corpo do "eu posso", construindo a autoestima na infância. Para além da consciência de um "eu penso que", enfatiza Merleau-Ponty (2018), a consciência é um "eu posso" (p. 192), pois "Sistema de potências motoras ou de potências perceptivas, nosso corpo não é objeto para um 'eu penso': ele é um conjunto de significações vividas que caminha para seu equilíbrio" (p. 212, grifo do autor).

Cabe não homogeneizar as visões de mundo das crianças, cada uma constrói sua experiência e percebe o mundo à sua maneira. Para uma das crianças o estado interno de ludicidade não era evidenciado: "não gosto de yoga porque não tem muita brincadeira, queria que tivesse uma brincadeira muito legal". E algumas ficavam incomodadas por sentir dor: "quando fica difícil fica doendo, quando faz a yoga difícil, aquela de puxar o dedo com as mãos"; "porque tem que esticar o corpo e dói". As crianças podem apresentar uma multiplicidade de sentidos às suas experiências e precisam ser acolhidas em seus pontos de vista. "Pensar-agir fenomenologicamente é positivar o fenômeno infância e aceitar a criança como ela é" (MACHADO, 2013, p. 253), como alguém que se posiciona no mundo (TELLES, 2014). O yoga ao ser apresentando à criança é passível de leitura, interpretação e produção.

A motricidade expressa nos ásanas e nos yamas e nyamas permite à criança observar-se e gerar sentimentos positivos em relação a si, bem como o cultivo de bons pensamentos e palavras, como sugere o nyama saucha, encaminhando também para o cuidado de si. Sensibilidade e construção do pensamento são codependentes, na ótica merleau-pontiana.

Martins e Cunha (2011) relatam que na experiência corpóreo-sensorial do yoga a criança vai sendo conduzida (e se conduz) a investigar o seu próprio corpo, se envolvendo com as posturas e incorporando as suas qualidades.

Assim, nas posturas dos guerreiros, ao visualizar-se como um deles, a criança interioriza sua força e coragem. Sente-se bela como uma borboleta, corajosa como um leão, grande como uma girafa. A árvore, que tem suas raízes fincadas no solo e dança com seus galhos ao movimento do vento, a faz sentir-se firme e equilibrada, mas 
também flexível, aberta ao inesperado. A vitalidade do ser criança é desvelada no corpo poético da saudação ao sol: "com música parece uma dança", disse uma criança que também relacionou o sol com um estado alegre e quente.

As crianças mencionavam que "yoga é muito divertido", "eu gostei muito dessa brincadeira diferente", "faz mais vezes", "gosto do yoga porque amo os animais", "gosto porque eu me divirto muito", "eu adoro as brincadeiras", "eu sou feliz quando estou no yoga", evidenciando a imersão lúdica e o sentimento de contentamento consigo (de "ser") e com o momento vivido, estado de si enfatizado pelo nyama santosha.

O protagonismo e a capacidade de transformação da cultura pelas crianças instauravam uma forma própria de expressão, na qual mudavam/inventavam a ordem das brincadeiras, recriavam/construíam as regras para si e para o grupo, brincando à sua maneira e ensinando uns aos outros. No processo coletivo de definições, a orientação e o respeito entre si nas brincadeiras eram potencializados. Associar o valor de ahimsa às brincadeiras, versando sobre o respeito ao outro, aos animais e à natureza (além de si), impulsionou atitudes como aguardar a vez do amigo numa brincadeira e resolver conflitos sem brigar ou ofensas, construindo o diálogo, a cooperação e a convivência harmoniosa.

A criança é ativa no falar, no tocar, no buscar conhecer e sentir. Elas diziam que não gostavam quando o amigo enganava ou mentia na brincadeira e que por isso entendiam que não deveriam fazer o mesmo com o outro. Chamá-las a compreender o valor do yama satya cultiva a verdade e o não mentir para si mesmo nem para os outros. A honestidade, fortalecendo o agir sincero e com veracidade (yama asteya) também eram incentivados nos momentos de massagem com bolinhas de borracha, em duplas e trios, com movimentos nas costas e nas mãos dos colegas, que aproximavam as crianças visando anular sentimentos de rejeição sobre o outro. Foram momentos significativos em que elas tiveram muito cuidado com o toque nos amigos, paciência e souberam dizer quando algo as incomodava sem agressão verbal.

Nesse coletivo enfatizávamos, também, a importância do compartilhar e do desapego, como sugere o yama aparigraha: "Eu brinco e todo mundo brinca também", se referiu uma criança enquanto compartilhava os brinquedos no grupo.

Desse modo, com a permeabilidade dos ásanas com os yamas e nyamas, aproximando a vivência e a filosofia aos modos de ser criança, as narrativas construídas no yoga se transformam em narrativas da vida.

A motricidade é inseparável de uma visão do mundo, de sua significação simbólica, ao passo que é esta mesma visão a condição da criação da expressividade que integra o mundo cultural. Como uma intencionalidade original, a motricidade " [...] não é como uma serva da consciência, que transporta o corpo ao ponto do espaço que nós previamente nos representamos" (MERLEAU-PONTY, 2018, p. 193). Nosso corpo não se move no espaço simplesmente, mas ele desenha o espaço.

Nas brincadeiras com ásanas a respiração é a fonte da concentração e da energia. Os pranayamas permitem que a criança perceba sua respiração, o caminho do ar pelo seu corpo e as sensações que isto provoca. Aprende a controlar o ato de respirar, inalando e exalando, fazendo pausas, prendendo o ar, respirando profundamente. Mas, a respiração, no yoga, mais que um processo fisiológico, é um elemento da vida que se relaciona com a consciência corporal, a concentração e a emoção e contribui para o fluxo de pensamentos e o equilíbrio e calma na tomada de decisões. Uma criança lembrou que "quando você estiver estressado, você tem que respirar fundo".

Cheirar a flor e soprar a vela, ao conferir sentido lúdico para o pranayama e estimular os sentidos, levava as crianças ao relaxamento e descanso. Assim como ritmar a respiração brincando com a mola maluca, na corrida de bolinhas, com a respiração da 
abelha. A respiração do barquinho viajante, com o barquinho de papel construído pelas crianças posicionado no abdômen, permitiu guiar-se por uma aventura no mar, explorando diferentes ritmos de respiração ao imaginar o movimento do barquinho ora em águas turbulentas ora em águas tranquilas.

Pratyahara e dharana são outros dois passos do yoga que se entrelaçam ao processo de concentração pela respiração, posturas e valores. O primeiro traz a restrição da atenção ao focá-la na ação do presente, evitando ceder aos excessos de informação do ambiente. É um processo de controle dos sentidos que leva ao passo seguinte, potencializando o alcance de um estado de concentração que propicia a percepção de si e estados de relaxamento.

No relaxamento, uma das ocasiões para proporcionar tais percepções, as crianças deitavam, alongavam-se e acomodavam-se ao seu jeito. Eram conduzidas a manter a atenção em um ponto de cada vez, de modo a perceber os movimentos do corpo próprio: a respiração, o ritmo dos batimentos do coração, o calor na pele, o frio do vento, perceber os pés que as levam a tantos lugares. Contudo, ficar em silêncio, sem se movimentar, fechar os olhos e, enfim, relaxar é um desafio para as crianças pequenas. "ah, eu não gosto é de ficar parado! Às vezes, a professora apaga a luz e a gente fica assim... parado, sem fazer nada", gesticulava indicando a posição do corpo deitado e com os olhos fechados, com seu corpo todo contando a sua percepção.

Cada criança, com sua individualidade, apresentou reações diferentes a esses momentos, com mais ou menos atenção, algumas sonolentas ao final, mas no decorrer do ano todas se permitiam relaxar e aquietar por alguns minutos. As crianças recorriam à importância de não se enganar (satya) no momento de fechar os olhos. Os momentos de pausa para perceber-se são fundamentais. Diziam ao final que se sentiam bem: " $f a z$. bem", "a gente fica melhor"; relaxadas: "ah, eu me sinto relaxando", "é bom porque relaxa", "é muito relaxante", "eu aprendi a relaxar"; e tranquilas: "eu me sinto tranquila e também me sinto mais calma", "eu me sinto mais calmo, nem choro mais".

Centrar a atenção no momento presente, no relaxamento, na postura, na brincadeira, na respiração, oportuniza às crianças a contemplação de si, tranquilidade e aquietação dos pensamentos. Experiências de quietude e de silêncio para fomentar um outro estado de percepção e atenção corporal ampliam, também, a capacidade de observar e de se entregar aos acontecimentos com centralidade em cada um deles, trabalhando a atenção plena. As tarefas escolares com os horários rigidamente demarcados (para comer, brincar, dormir, pintar, conversar), a intelectualização prematura e o excesso de estímulos do mundo digital (para uma parcela da população) são alguns dos mecanismos contemporâneos que descorporificam a experiência infantil e concorrem com a autoentrega ao brincar, diminuindo a intensidade do corpo próprio, o que pode causar ansiedade, afetar as relações e a autoestima.

Nos pressupostos fenomenológicos é o corpo que apreende os sentidos, como uma expressão criadora que se constitui na teia dos diferentes olhares sobre o mundo, experienciados e construídos pela motricidade. Nesse processo, as descobertas vão se incorporando ao mundo infantil.

\section{DAS DESCOBERTAS E SENTIDOS DA EXPERIÊNCIA: O SI, O OUTRO E O NÓS}

Corporeidade não é um mero conceito, diz respeito a uma atitude alicerçada na existencialidade humana (MOREIRA; CAMPOS; SIMÕES, 2019). Precisamos redimensionar a corporeidade no processo educativo não como conteúdo de ensino de uma determinada unidade programática, mas como o fio condutor da existência, da 
construção do pensamento e da emancipação humana, permitindo construir uma outra concepção de corpo e do ser em movimento, do existir, do conhecer, do sentir e do viver.

Merleau-Ponty (2018) ao se recusar a conceber a experiência do corpo próprio em oposição ao movimento reflexivo como dimensões polarizadas e inconciliáveis, defendia que é a percepção o fundo dos nossos contatos com o mundo e com os outros, a articulação corpo-mundo, aquilo o que nos toca, nossa sensibilidade, presente antes mesmo do pensamento elaborado. Primeiro sentimos o estar no mundo, vivenciamos o mundo imediato (experiência do ser no mundo), para então elaborarmos um pensamento (pensar é uma ação corporal). Por isso, sem a experiência do ser no mundo - um mundo não distante de mim ou uma existência à parte, mas entrelaçado a mim - não há conhecimento. $\mathrm{O}$ conhecimento origina do corpo.

Com as experiências as crianças foram atribuindo seus sentidos e descobrindo o yoga: "yoga são as posturas", "é quando a gente fica calmo", "é essas coisas que a gente faz aqui, que brinca, dança, canta, fica deitado", "yoga é quando a gente respira", "eu aprendi que quando a gente faz yoga, nosso corpo fica mais acordado", "no yoga a gente brinca sem brigar".

É o corpo que possibilita a criação de sentidos e do mundo simbólico. As crianças percebem com os sentidos e elaboram com o corpo todo, com a inteligência, com a representação, com o simbólico. O corpo, como "nosso meio geral de ter um mundo" transita numa relação permanente entre o gesto e a conservação da vida; "[...] passando de seu sentido próprio a um sentido figurado" (MERLEAU-PONTY, 2018, p. 203) gera novos núcleos de significação, como no caso dos movimentos específicos das práticas corporais. Significação que somente é alcançada pela cultura.

Assim, percepção e motricidade entrelaçam os mundos sensível e inteligível e tecem as significações do vivido, de uma maneira própria ao mesmo tempo que relacional. O corpo próprio permite aprender a ver, a escutar, a cheirar, a se-movimentar de maneiras específicas. Interrogar com os sentidos enriquece e reorganiza o esquema corporal (MERLEAU-PONTY, 2018). A compreensão fenomenológica do ser criança e do brincar passa pelos existenciais corporeidade, mundaneidade e outridade, nas relações criança-corpo, criança-outro, criança-mundo (MACHADO, 2010).

Nesse encaminhamento as descobertas do corpo também foram acentuando a relação criança-corpo com o corpo-lúdico: "é o que a gente usa para brincar", "é com ele que a gente brinca, pula, corre"; com sua materialidade existencial: "corpo são os ossos, nosso esqueleto"; com sua sensibilidade: "corpo é ser feliz"; com sua relação eumundo: "é eu, é minha mãe e minha irmã"; "corpo é isso! [apontando para si]".

Precisamos valorizar o que é dado pelos sentidos e não somente o que as crianças são capazes de elaborar pelo pensamento. A percepção, como modo de sentir o mundo não depende do julgamento de valores para acontecer: "O real é um tecido sólido, ele não espera nossos juízos para anexar a si os fenômenos mais aberrantes, nem para rejeitar nossas imaginações mais verossímeis" (MERLEAU-PONTY, 2018, p. 6). Logo, a percepção não atrapalha o processo cognitivo como requeria a filosofia clássica.

Sentir-se um "eu" revelou a criança em seu ser corpóreo. A criança-corpo que constrói sentires, fazeres e saberes encarnados. Expressões como: "eu me sinto vivinho quando brinco de yoga", "corpo é o que eu sou, olha aqui" e "eu aprendi a confiar em mim" situam a condição de existência corporificada e que é a consciência que aprende com o corpo a refletir.

Não é possível apreender o mundo somente pela razão, pela capacidade de pensamento e de racionar. Também não há consciência sem sensibilidade, sem sentimento e emoções. A consciência, presentificada no mundo pelo corpo, é sempre 
consciência de algo e passa necessariamente pelas experiências vividas e o sentido dado a elas, confirma Merleau-Ponty (2018). A consciência de si é sintetizada entre a percepção e o pensamento, como resultado da motricidade e da intencionalidade do semovimentar da criança.

Chauí (2000, p. 307) destaca a postura de Merleau-Ponty ao buscar ultrapassar a miopia do dualismo epistemológico corpo e consciência, pois "Não somos uma consciência reflexiva pura, mas uma consciência encarnada num corpo. [...] Não somos pensamento puro, pois somos um corpo. Não somos uma coisa natural, pois somos uma consciência". E é só o corpo próprio que compreende essa unidade.

A automassagem com bolinhas de borracha, conduzida pela contação de história percorrendo os pés, pernas, barriga, costas, braços, mãos, rosto, contribuía para explorar a percepção do corpo e o autoconhecimento - " $a$ h, eu me sinto relaxando... hãa, me sinto mexendo meu corpo, eu aprendo algumas partes que eu não sei muito... tipo... ombro, um dedinho do pé, esse aqui pequenininho ó". O autoconhecimento dialoga com o nyama svadhyaya que recomenda o estudo sobre si mesmo. Outra proposta, a de desenhar-se e desenhar os colegas, favoreceu um momento tanto de reconhecimento de si como do outro, identificando os traços semelhantes e diferentes, numa relação criança-outro: "olha tia, olha meu tamanho!"; "a gente ficou diferente"; "opa, esse não sou eu"; "olha, acho que é você aqui, parece seu cabelo [indicando um colega]". As crianças demostraram um olhar sensível durante essas vivências, percebendo e conhecendo mais sobre elas mesmas, sobre o corpo, e a cada experiência foi-se construindo a ideia de um corpo indivisível.

A consciência corporal, como integração ativa do corpo, é uma unidade que considera o sujeito em situação e, assim, vai além do reconhecimento das partes do corpo, sendo a interpretação perceptiva das vivências elaborada com o corpo todo (NÓBREGA, 2019).

A criança percebe-se o tempo todo. A criança quando brinca toca o outro, é tocada. Fala, ouve, produz sons. Vê e é vista. Vê-se a si mesma, toca-se, ouve-se. Reconhece-se e reconhece o outro, tão corpo quanto ela mesma, mas com todas as singularidades, aprendendo a conviver com a diversidade de ser, de pensar, de estar e de viver. Antes mesmo da palavra vem o gesto:

\footnotetext{
Meu corpo estende a mão e toca outra mão em outro corpo, vê um olhar, percebe uma fisionomia, escuta uma outra voz: sei que diante de mim está um corpo que é meu outro, um outro humano habitado por consciência e eu o sei porque me fala e, como eu, seu corpo produz palavras, sentido (CHAUÍ, 2000, p. 311).
}

É orgânico no yoga a ação e a filosofia com a expressão, a concentração, a percepção corporal que permitem interpretar o que se passa consigo, orientando ações, caminhando para o reconhecimento de si e do outro, mais, para o reconhecimento do "nós".

Corporeidade como condição humana não se reduz a um corpo individual. A corporeidade vincula-se com outros corpos e na sua relação com o mundo (ZIMMERMANN; SAURA, 2019). Nessa compreensão, pensar corporeidade não significa tratar somente de um conhecimento de si, individual, como se veria numa dicotomia entre o racional e o sensível, entre o objetivo e o subjetivo; nem mesmo reduzir o social face à supremacia do indivíduo, mas "A subjetividade aparece na perspectiva fenomenológica de educação como condição necessária ao processo de desalienação individual e coletiva" (NÓBREGA, 2019, p. 82), como modo de cada um 
perceber-se capaz de atuar na produção das estruturas sociais, pois as experiências são edificadas na intersubjetividade e na relação sujeito-mundo.

Para conhecer e saber quem eu sou preciso perguntar quem é o outro. Como seres conscientes do que realmente somos, social e individualmente, precisamos reconhecer que a consciência não é só um atributo pessoal, mas é a consciência do outro também, um valor coletivo porque somos seres interdependentes. Numa sociedade individualista, despreocupada com os efeitos do humano sobre o outro e sobre o planeta, é indispensável pensar que eu me constituo em função do outro. A consciência expandida prima pela capacidade de perceber que estamos no outro como o outro está em nós. Machado (2010, p. 28) enfatiza que na lente fenomenológica "o outro sou eu", não há nada no mundo (pessoa ou coisa) por si só, descontextualizada da cultura humana.

O movimento de jogar-se na compreensão do outro, no seu drama, vem no sentido de cultivar a empatia como uma ação que exige movimento. Na motricidade infantil, nesse caso pelas vivências das brincadeiras de yoga no coletivo, vivenciando o atravessamento dos valores nas ações, as crianças foram percebendo a conexão com os pares e a descoberta do valor do outro: "a gente aprende no yoga a ser bom amigo $e$ cuidar dos animais"; "não posso machucar ele porque eu ia ficar triste se ele me machucasse"; "quando a gente brinca junto é tão mais tão legal!", fazendo a síntese entre a criança-corpo, criança-outro e criança-mundo.

Colaboração, paciência e respeito com os colegas evoluíram significativamente no decorrer do ano, enriquecendo o conviver e o dialogar, o saber lidar com novas situações, o interagir com desenvoltura, espontaneidade e harmonia com aqueles que circundam sua vida. A descoberta do outro é atravessada pelo se-movimentar em direção ao outro, consciência esta tomada como atenção, presença, generosidade, gentileza, relacionamento amoroso e cuidadoso, importando-se com as pessoas e fortalecendo os vínculos afetivos, pois “[...] quer se trate do corpo do outro ou de meu próprio corpo, não tenho outro meio de conhecer o corpo humano senão vivê-lo, quer dizer, retomar por minha conta o drama que o transpassa e confundir-me com ele" (MERLEAU-PONTY, 2018, p. 269, grifo do autor).

A corporeidade e a diversidade das manifestações corporais podem despertar nas crianças o desejo do encontro com as reflexões, os sentires e os saberes. Sentir e agir de maneira que possam reconhecer e valorizar as diferentes culturas e modos de pensar e de ser que coexistem em nossa sociedade. Reconhecer que são seres interrelacionais que se constituem e crescem na complexa teia de relações da rede da vida, construídas com os outros e com o entorno. Como tenciona Merleau-Ponty (2018, p. 18), é na "[...] intersecção de minhas experiências, e na intersecção de minhas experiências com aquelas do outro, pela engrenagem de umas nas outras" que podemos construir redes de relações para a expansão da experiência vivida.

\section{CONSIDERAÇÕES}

Refletir sobre as relações entre a corporeidade e a educação infantil em interlocução com as vivências de yoga das crianças nos permite reforçar que o corpo próprio e o mundo vivido revelam-se pela motricidade, pela intencionalidade dos gestos em seus modos de se expressar, pela atribuição de sentidos às experiências que perpassam as relações consigo e com os outros.

O yoga, com suas posturas e respirações como formas de expressão e percepção, com seus valores para a boa (con)vivência e com a concentração e a interiorização dos sentidos, pode contribuir para promover um olhar (e o aprender) sobre o si e o em si, 
reconhecendo suas emoções, ações e capacidade de criação, contemplando o ser em sua integridade. Potencializa, também, a escuta do outro, a sensibilidade e o afeto entre as crianças. Em sua realidade corpórea, as crianças imaginam, conhecem e comunicam com o yoga, percebendo a corporeidade que as atravessam.

Precisamos propiciar uma experiência corporal na educação infantil (e em todo o percurso escolar) em que o movimento não seja mecanizado, produtivo ou secundarizado. A lógica existencial guiada pela corporeidade e pela motricidade pode superar a concepção de existência pautada numa cultura de produção, de competição, de padrões corporais e de movimento. Se nos apropriamos do mundo pela motricidade e a educação visa à formação humana, as manifestações corporais podem potencializar este diálogo do ser-corpo-no-mundo, com criatividade, autonomia, criticidade, protagonismo e engajamento corporal/existencial.

Queremos um corpo próprio, com sua complexidade e multidimensionalidade, um corpo de ação, não o corpo negado, nem o corpo subalterno em seus gestos, com suas diferenças anuladas. Um corpo com suas sensibilidades e como fonte de conhecimento, considerando suas histórias, suas marcas, suas expectativas, suas múltiplas expressões. Um corpo como território da existência, político, consciente e sensível, singular e ao mesmo tempo plural, como uma unidade que ressoa no coletivo e na rede de construção da cultura.

A corporeidade é viva, é ser, é agir no tempo e no espaço, constante e incessantemente. $\mathrm{O}$ corpo se reinventa em suas potencialidades, em suas vibrações, em seus movimentos, em seus gritos, em seus silêncios. Exploremos outras possibilidades educativas, mais corporais, mais existenciais, mais humanas, mais significativas e emancipadoras, já que "O mundo é não aquilo que eu penso, mas aquilo que eu vivo; eu estou aberto ao mundo, comunico-me indubitavelmente com ele, mas não o possuo, ele é inesgotável" (MERLEAU-PONTY, 2018, p. 14), para que as crianças possam conhecer, manifestar e transformar cotidianamente sua corporeidade.

\section{REFERÊNCIAS}

BRASIL. Ministério da Educação. Diretrizes curriculares nacionais para a educação infantil. Brasília: MEC/SEB, 2010.

CHAUÍ, M. Convite à filosofia. São Paulo: Ática, 2000.

FEUERSTEIN, G. A tradição do yoga: história, literatura, filosofia e prática. 5 ed. São Paulo: Pensamento, 2001.

FLAK, M.; COULON, J. Yoga na educação: integrando corpo e mente na sala de aula. Florianópolis: Comunidade do Saber, 2007.

KUNZ, E.; COSTA, A. R. A imprescindível e vital necessidade da criança: brincar e se-movimentar". In: KUNZ, E. (org.). Brincar e se-movimentar: tempos e espaços de vida da criança. 2 ed. Ijuí: Ed. Unijuí, 2017. p. 13-37.

LE BRETON, D. Adeus ao corpo: antropologia e sociedade. 6 ed. Campinas: Papirus, 2013.

LEOPOLDO E SILVA, F. Sobre ética, Merleau-Ponty e fenomenologia: ecos de um diálogo com Renaud Barbaras. Phenomenological Studies - Revista da Abordagem Gestáltica, Goiânia, v. 25, n. 2, p. 185195, maio/ago. 2019.

MACHADO, M. M. Fenomenologia e infância: o direito da criança a ser o que ela é. Revista de Educação Pública, Cuiabá, v. 22, n. 49/1, p. 249-264, maio/ago. 2013. 
MACHADO, M. M. Merleau-Ponty \& a educação. Belo Horizonte: Autêntica Editora, 2010.

MARTINS, F. S.; CUNHA, A. C. Yoga com crianças: um caminho pedagógico-didáctico. In: SEMINÁRIO INTERNACIONAL DE EDUCAÇÃO FÍSICA, LAZER E SAÚDE, 7., 2011, Braga. Anais [...]. Braga: CIED, jul. 2011. p. 1-17.

MERLEAU-PONTY, M. Fenomenologia da percepção. 5. ed. São Paulo: Editora WMF Martins Fontes, 2018.

MERLEAU-PONTY, M. Psicologia e pedagogia da criança: curso da Sorbonne 1949-1952. São Paulo: Martins Fontes, 2006.

MOREIRA, W. W. Merleau-Ponty na sala de aula e na beira do campo: contribuições para a área da educação física/esportes. In: NÓBREGA, T. P.; CAMINHA, I. O. (org.). Merleau-Ponty e a educação física. São Paulo: Liber Ars, 2019. p. 21-37.

MOREIRA, W. W.; CAMPOS, M. V. S.; SIMÕES, R. Motricidade, corporeidade e complexidade: diálogos a partir do hemisfério sul. Motricidades: Revista da SPQMH, São Carlos, v. 3, n. 3, p. 167176, set./dez. 2019.

NÓBREGA, T. P. A atitude fenomenológica: o corpo-sujeito. In: NÓBREGA, T. P.; CAMINHA, I. O. (org). Merleau-Ponty e a educação física. São Paulo: Liber Ars, 2019. p. 69-91.

NÓBREGA, T. P. Qual o lugar do corpo na educação? Notas sobre conhecimento, processos cognitivos e currículo. Educação \& Sociedade, Campinas, v. 26, n. 91, p. 599-615, maio/ago. 2005.

SARMENTO, M. J. Gerações e alteridade: interrogações a partir da sociologia da infância. Educação \& Sociedade, Campinas, v. 26, n. 91, p. 361-378, maio-ago. 2005.

TELLES, T. C. B. A infância na fenomenologia de Merleau-Ponty: contribuições para a psicologia e para a educação. Revista do NUFEN, Belém, v. 6, n. 2, p. 4-13, 2014.

ZIMMERMANN, A. C.; SAURA, S. C. Corpo e espanto na filosofia de Merleau-Ponty. In: NÓBREGA, T. P.; CAMINHA, I. O. (org.). Merleau-Ponty e a educação física. São Paulo: Liber Ars, 2019. p. 119131.

Recebido em: 24 jul. 2020.

Aprovado em: 21 ago. 2020. 